\title{
Kaolin-Enhanced Superabsorbent Composites: Synthesis, Characterization and Swelling Behaviors
}

\author{
Mengna Chen ${ }^{1} \mathbb{D}$, Xuelong Chen ${ }^{2} \mathbb{D}$, Caiyan Zhang ${ }^{1}$, Baozheng Cui $^{1}$, Zewen Li ${ }^{1}$, Dongyu Zhao ${ }^{1}$ \\ and Zhe Wang $1, *$ (D)
}

Citation: Chen, M.; Chen, X.; Zhang, C.; Cui, B.; Li, Z.; Zhao, D.; Wang, Z. Kaolin-Enhanced Superabsorbent Composites: Synthesis, Characterization and Swelling Behaviors. Polymers 2021, 13, 1204. https://doi.org/10.3390/ polym13081204

Academic Editor: Edina Rusen

Received: 22 March 2021

Accepted: 2 April 2021

Published: 8 April 2021

Publisher's Note: MDPI stays neutral with regard to jurisdictional claims in published maps and institutional affiliations.

Copyright: (c) 2021 by the authors. Licensee MDPI, Basel, Switzerland. This article is an open access article distributed under the terms and conditions of the Creative Commons Attribution (CC BY) license (https:// creativecommons.org/licenses/by/ $4.0 /)$.
1 Department of Polymer Materials and Engineering, School of Chemistry and Materials Science, Heilongjiang University, Harbin 150080, China; Mengna999456@163.com (M.C.); zhangcaiyan061995@163.com (C.Z.); 2201459@s.hlju.edu.com (B.C.); lizewen145@126.com (Z.L.); zhaodyu@aliyun.com (D.Z.)

2 School of Material Science and Engineering, Nanyang Technological University, 50 Nanyang Avenue, Singapore 639798, Singapore; xchen014@e.ntu.edu.sg

* Correspondence: zhe.wang@msn.com

\begin{abstract}
One type of low-cost and eco-friendly organic-inorganic superabsorbent composite (SAPC) was synthesized by free radical polymerization of acrylic acid (AA), starch (ST), sodium alginate (SA) and kaolin (KL) in aqueous solution. The structure and morphology of the SAPC were characterized by Fourier transform infrared spectrometer (FT-IR), scanning electron microscope (SEM), $X$-ray diffraction (XRD) and thermogravimetric analysis (TGA). The influence of different reaction conditions on water absorption of SAPC, i.e., SA and KL contents, AA neutralization degree (ND), potassium persulfate (KPS) and N, N'-methylenebisacrylamide (MBA) loading were systematically studied. Under the optimal synthesis conditions, very high water absorption of $1200 \mathrm{~g} / \mathrm{g}$ was achieved. The swelling kinetic mechanism of SAPC was studied by pseudo-second order swelling kinetics model and Ritger-Peppas model. The performances of SAPC under different environments were tested and results revealed that this new SAPC had excellent swelling capacity, high water retention, good salt tolerance in monovalent salt solution ( $\mathrm{NaCl}$ solution) and good $\mathrm{pH}$ tolerance between 4 and 10 .
\end{abstract}

Keywords: sodium alginate; starch; kaolin; free radical polymerization; superabsorbent composites; characterization; swelling behavior

\section{Introduction}

Superabsorbent polymers (SAPs) are one type of three-dimensional (3D), cross-linked hydrophilic materials that can absorb and hold a large amount of water within a certain period of time [1-4]. Before the emergence of SAP, natural biomass materials, such as cotton, have been used for traditional absorbents [5]. These materials absorb water through capillarity, yet with low water absorption capacity, and cannot retain water for a long time, making them unsuitable for many life and industry applications. By contrast, SAP mainly absorbs water through chemical adsorption, with efficient water absorption and large water retention capacity [6]. Owing to excellent performance, SAP has been widely used in diversified fields, such as personal care, industry, chemicals, forestry, agriculture, wastewater treatment and drug-delivery systems [7-9].

Although with wide applications, SAP still has several key issues that need to be addressed, such as high synthesis costs, potential toxicity and serious environmental influences $[10,11]$. To reduce production costs and improve performance, many inorganic clay minerals (montmorillonite, kaolin, bentonite and attapulgite) and natural polymeric materials such as polysaccharides (starch, sodium alginate, cellulose, chitosan and their derivatives) have been used to synthesize environmentally friendly organic-inorganic superabsorbent composites (SAPCs) [12-14]. 
Kaolin is a hydrous aluminosilicate with layered structure, which has advantages of large specific surface area, large cation exchange capacity and low cost $[15,16]$. The addition of kaolin can not only significantly reduce the production cost, but is also able to improve water absorption, gel strength, thermal stability and mechanical properties of the final products $[17,18]$.

Starch is a natural polysaccharide, mainly composed of amylose and amylopectin [19]. The former possesses a linear chain composed of $\alpha$-1,4-linked glucose unites, while the latter has a highly branched chain of $\alpha$-1,4-linked glucose units interlinked by $\alpha$-1,6-linked bonds [20]. Sodium alginate, an abundant natural polysaccharide extracted from various species of brown seaweed, is composed of $\beta$-1,4-linked D-mannuronic acid and $\alpha$-1,4-linked L-guluronic acid with various proportions, which can be arranged into different sequences in the polymeric backbone [21,22]. Taking advantages of excellent properties, such as biocompatibility, biodegradability, low cost and low toxicity, starch and sodium alginate have become ideal backbones for the synthesis of SAP [23]. By now, graft polymerization of vinyl monomers such as acrylamide, acrylonitrile, and acrylic acid with starch and sodium alginate, respectively, has been reported. Erdener Karadağ et al. synthesized novel composite sorbent AAm/MA hydrogels containing starch and kaolin used for water sorption and dye uptake [24]. Jihuai Wu et al. fabricated one type of starch-graft-acrylamide/kaolin superabsorbent composite with water absorbency 4000 times higher than its own weight [25]. Linhui Zhu et al. studied the adsorption behaviors of sodium alginate graft poly(acrylic acid-co-2-acrylamide-2-methyl propane sulfonic acid)/kaolin hydrogel composite towards dyes [26]. Sodium alginate graft poly(acrylic acid-co-acrylamide)/kaolin composite hydrogel has also been prepared by Yaoji Tang et al [27]. However, there are few reports on the simultaneous introduction of starch and sodium alginate into the system to graft polymerize with vinyl monomer. It is reported that the use of a polysaccharide mixture in SAP synthesis shows better mechanical stability and water retention capacity compared to a single polysaccharide [28]. The addition of sodium alginate can improve $\mathrm{pH}$ sensitivity of starch-based SAP [29]. In addition, the preparation route of SAP from sodium alginate nowadays is attractive as to make full use of marine resources and reduce manufacture cost and pollution. Nevertheless, the viscosity of sodium alginate solution is extremely high. During the synthesis of alginate-based SAP, the viscosity of the reaction system often sharply increases due to the addition of sodium alginate, which restricts the movement of reactants and reduces the monomer conversion rate. It is hypothesized that adding a certain amount of starch can reduce the content of sodium alginate and viscosity of the system.

Based on these reasons, a novel organic-inorganic SAPC was synthesized by free radical copolymerization with acrylic acid, starch, sodium alginate and kaolin. The structure of the SAPC was characterized by Fourier transform infrared spectrometer, scanning electron microscope, X-ray diffraction and thermogravimetric analysis. The influence of different reaction conditions on water absorption of SAPC was studied. A pseudo-second order kinetics model and Ritger-Peppas model also illustrated the swelling kinetic mechanism of SAPC. The performance of this new SAPC was tested. Results showed that the SAPC had excellent swelling capacity, salt tolerance, water retention and $\mathrm{pH}$ sensitivity.

\section{Experimental}

\subsection{Materials}

Starch (ST, food grade) was purchased from Shandong Lejiake Food Co., Ltd. (Dezhou, Shandong, China). Sodium alginate (SA, analytical grade) was from Shanghai Yuanye Biotechnology Co., Ltd. (Shanghai, China). Acrylic acid (AA, analytical grade) was purchased from Tianjin Zhiyuan Chemical Reagent Co., Ltd. (Tianjin, China), kaolin (KL, chemically pure) was purchased from Shanghai Fengxian Fengcheng Reagent Factory (Shanghai, China), and potassium persulfate (KPS, analytical grade) was purchased from, Tianjin Komiou Chemical Reagent Co., Ltd. (Tianjin, China). N, N'-methylenebisacrylamide (MBA, chemically pure) was obtained from Tianjin Guangfu Research Institute of Fine 
Chemical (Tianjin, China). Sodium hydroxide $(\mathrm{NaOH}$, analytical grade) was supplied by Tianjin Tianli Chemical Reagent Co., Ltd. (Tianjin, China). All solutions were prepared with distilled water.

\subsection{Synthesis of SAPC}

The ST ( $3 \mathrm{~g})$ was dissolved in distilled water $(40 \mathrm{~mL})$ and then placed in a $500 \mathrm{~mL}$ four-port flask with a condenser, a nitrogen tube and a mechanical stirrer. The solution was heated to $85^{\circ} \mathrm{C}$ and continuously stirred for $1 \mathrm{~h}$. Then, the solution of SA was added to the flask and continued to stir until temperature dropped to $50{ }^{\circ} \mathrm{C}$, and then KPS was added to generate radicals. After the temperature reached $70{ }^{\circ} \mathrm{C}$ and stirring for $15 \mathrm{~min}$, a mixture containing KL, MBA and partially neutralized AA (20 mL AA, neutralized AA with $25 \%(w / w) \mathrm{NaOH}$ solution under ice bath conditions) was added to the above system, followed by reaction for $3 \mathrm{~h}$. A nitrogen purge was used throughout the process. The product was dried in a vacuum oven at $60^{\circ} \mathrm{C}$ until the weight stabilized. Afterwards, the product was milled, and the size of all powder products used for testing was about 80 mesh.

For comparison, the synthesis of neat SAP was carried out in the same way except without KL. The structure of ST and SA is shown in Scheme 1, while the mechanistic pathway for synthesis of SAPC is shown in Scheme 2.

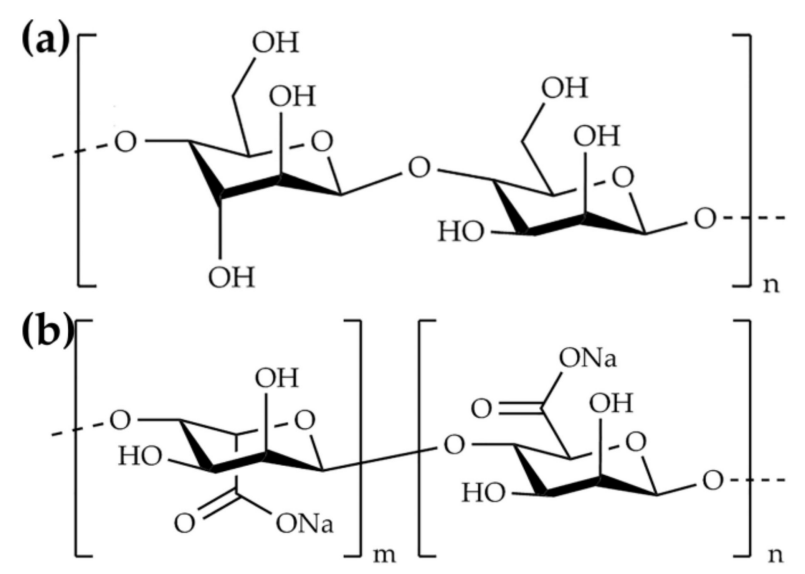

Scheme 1. Structure of (a) starch (ST) and (b) sodium alginate (SA).

\subsection{Characterization}

A Fourier transform infrared spectrometer (FT-IR; Bruker, Equinox 55, Mannheim, Germany) was used to record the infrared spectra of raw materials and products in the range of 4000-400 $\mathrm{cm}^{-1}$. The morphology of the products was observed with a scanning electron microscope (SEM; Hitachi, S-4800, Tochigi, Japan). The crystal structure of the sample was examined by X-ray diffraction (XRD; Bruker, D8 ADVANCE, Mannheim, Germany). The thermal stability of the products was analyzed by thermogravimetric analysis (TGA; Mettler, TGA/DSCI, Greifensee, Switzerland) from 35 to $800{ }^{\circ} \mathrm{C}$ with heating rate $10^{\circ} \mathrm{C} \mathrm{min}^{-1}$ under nitrogen atmosphere. 


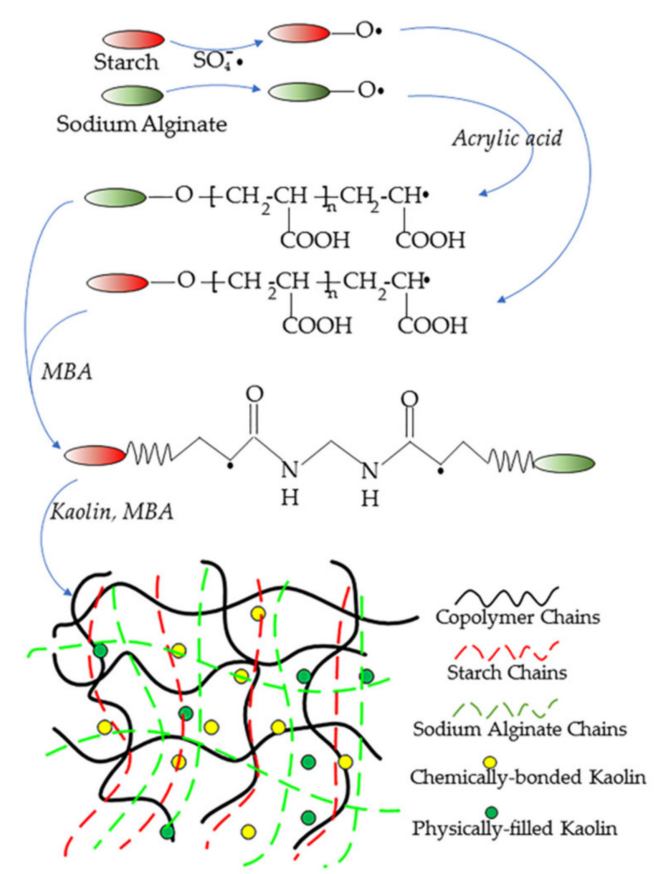

Scheme 2. The mechanistic pathway for synthesis of superabsorbent composite (SAPC).

\subsection{Performance Test of SAPC}

\subsubsection{Swelling Ratios}

To determine the swelling ratio, dry composites $(0.1 \pm 0.001 \mathrm{~g})$ were immersed in $500 \mathrm{~mL}$ of solutions (distilled water, various salt solutions and $\mathrm{pH}$ solutions) for $4 \mathrm{~h}$ at room temperature to achieve equilibrium. The swollen product was filtered through a 100-mesh screen to remove excess moisture and then weighed. Each specimen was tested thrice, and the average value was used. The water absorbent capacity was calculated using the following Equation (1):

$$
Q_{e q}=\frac{\left(m_{1}-m_{0}\right)}{m_{0}}
$$

where $Q_{e q}$ is the water absorbent capacity and $m_{0}$ and $m_{1}$ are the mass of the dried and swollen products, respectively.

\subsubsection{Swelling Kinetics}

The pre-weighed dry product $(0.1 \pm 0.001 \mathrm{~g})$ was added into distilled water $(500 \mathrm{~mL})$, and swelled for a period of time (5, 10, 15, 30, 45, 60, 120, 180 and $240 \mathrm{~min})$. The water absorption at time $t$ was measured by the method described in Section 2.4.1.

\subsubsection{Swelling in Salt Solutions}

$\mathrm{NaCl}$ and $\mathrm{FeCl}_{3}$ were used to prepare salt solutions with different concentrations $(0.02-0.1 \mathrm{~mol} / \mathrm{L})$. The pre-weighed dry product $(0.1 \pm 0.001 \mathrm{~g})$ was dispersed in various salt solutions $(500 \mathrm{~mL})$, and water absorption was measured by the method described in Section 2.4.1.

\subsubsection{Water Retention Measurement}

The fully swollen product $(80 \mathrm{~g})$ was placed in petri dishes at various temperatures $\left(25,45\right.$ and $\left.60^{\circ} \mathrm{C}\right)$, and then weighted every $2 \mathrm{~h}$. According to Equation (2), water retention of the product was calculated:

$$
W_{r}=\frac{\left(M_{t}-M_{0}\right)}{\left(M_{1}-M_{0}\right)} \times 100 \%
$$


where $W_{r}$ is the water retention rate of product, $M_{t}$ is the mass of the swollen product at time $t, M_{0}$ is the mass of the dry product and $M_{1}$ is the initial weight of the fully swollen products.

\subsubsection{Swelling Measurement in Buffer Solutions}

The buffer solutions (hydrochloric acid and sodium hydroxide solutions) with $\mathrm{pH}$ values from 2 to 12 were prepared to test the $\mathrm{pH}$ sensitivity of the SAPC. A $\mathrm{pH}$-meter (PHS-3C, accuracy is \pm 0.01 ) provided by Shanghai INESA Scientific Instrument Co., Ltd. (Shanghai, China) was used to detect the $\mathrm{pH}$ value of the solution. Then, the dry product $(0.1 \pm 0.001 \mathrm{~g})$ was dispersed in various buffer solutions $(500 \mathrm{~mL})$, and water absorption was calculated according to Equation (1).

\section{Results and Discussion}

\subsection{FT-IR Analysis}

The FT-IR spectra of the ST, SA, SAP, SAPC and KL are shown in Figure 1. The FTIR spectrum of ST is shown in Figure 1a, peaks at 1158, 1081 and $1005 \mathrm{~cm}^{-1}$ were the stretching vibration of the C-O-C bond $[30,31]$. After polymerization, these peaks shifted and weakened. As shown in the spectra of SA (Figure 1b), the strong bands at 1610 and $1410 \mathrm{~cm}^{-1}$ were due to the asymmetric and symmetric stretching vibrations of $-\mathrm{COO}^{-}$ groups, respectively [32]. The peak at $1032 \mathrm{~cm}^{-1}$ was related to the stretching vibration of C-OH [33], which moved to $1030 \mathrm{~cm}^{-1}$ and $1036 \mathrm{~cm}^{-1}$, respectively, after polymerization, and the intensity of this peak weakened significantly. Figure 1c shows the FT-IR spectrum of SAP, the absorption peak at $3469 \mathrm{~cm}^{-1}$ was attributed to the stretching vibration of $-\mathrm{OH}$, and three new peaks appeared at 1711, 1567 and $1409 \mathrm{~cm}^{-1}$. The peak at $1711 \mathrm{~cm}^{-1}$ may be related to the ester group formed during graft polymerization. Also, the new absorption at 1567 and $1409 \mathrm{~cm}^{-1}$ could be ascribed to the asymmetric and symmetric stretching of $-\mathrm{COO}^{-}$, respectively. These results showed that both ST and SA were involved in the grafting reaction. In the infrared spectrum of KL (Figure 1e), the absorption peaks of $-\mathrm{OH}$ were observed at 3696-3621 $\mathrm{cm}^{-1}$ [25]. As revealed in Figure 1d,e, the -OH peak shifted from $3469 \mathrm{~cm}^{-1}$ to $3457 \mathrm{~cm}^{-1}$, and a characteristic Si-O peak was observed at $471 \mathrm{~cm}^{-1}$, which indicated that $-\mathrm{OH}$ on $\mathrm{KL}$ was also involved in the reaction.

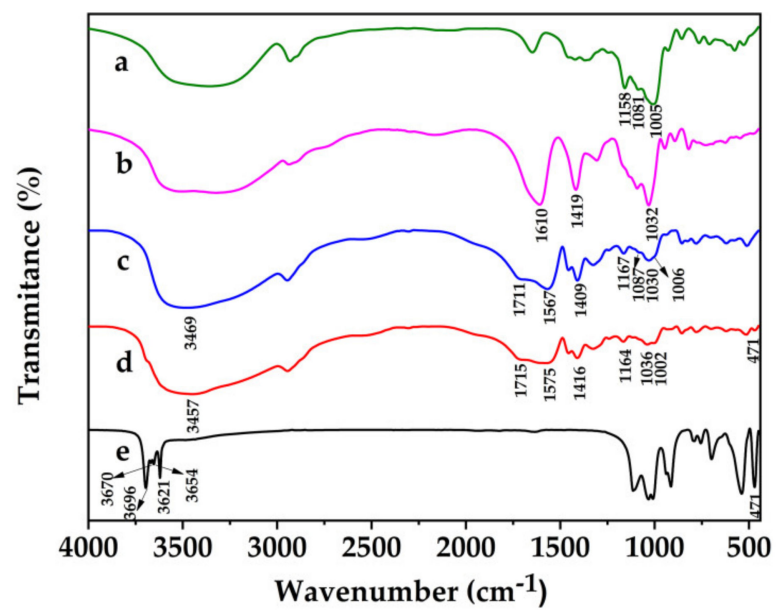

Figure 1. FT-IR spectra of (a) starch (ST), (b) sodium alginate (SA), (c) superabsorbent polymer (SAP), (d) superabsorbent composite (SAPC) (4 wt. \% KL) and (e) kaolin (KL).

\subsection{Morphology}

The appearance of SAPC at different states is exhibited in Figure 2a,b. The dried SAPC was a light-yellow solid, while the swollen SAPC was a transparent hydrogel. The volume of dried SAPC was significantly smaller than fully swollen SAPC. 

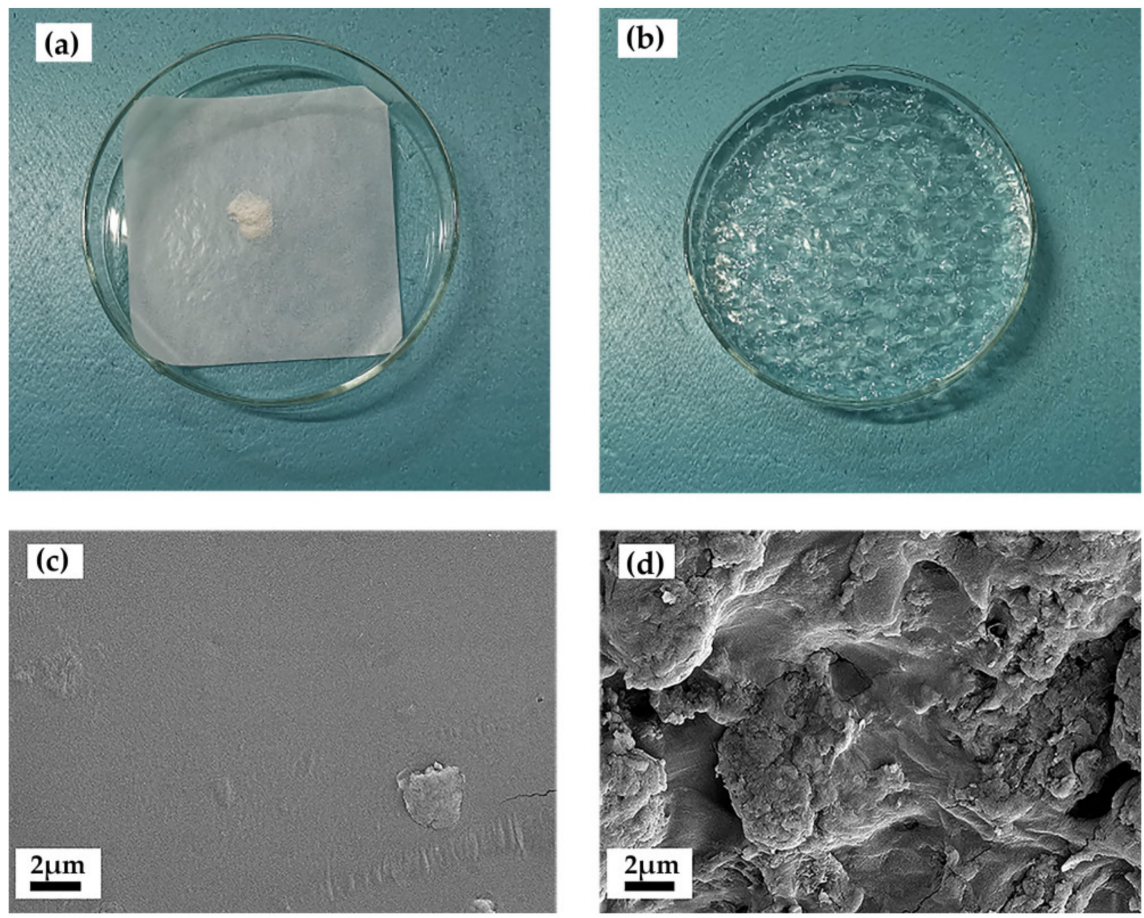

Figure 2. Digital images of (a) dried SAPC (80 mesh) and (b) swollen SAPC. SEM of (c) SAP and (d) SAPC ( 4 wt. \% KL); the scaling bars are $2 \mu \mathrm{m}$.

SEM of dried SAP and SAPC are shown in Figure 2c,d. The surface of SAP was compact and smooth, making it not conducive to the liquid entering into the polymer network. By contrast, after addition of KL, the surface of SAPC displayed a more rough and loose morphology with porous structure.

\subsection{XRD Analysis}

The XRD patterns of KL, SAPC and SAP are shown in Figure 3. The strong peak of $\mathrm{KL}$ at $2 \theta=12.59^{\circ}$ had an interplanar distance of $\mathrm{d}=0.702 \mathrm{~nm}$. This peak shifted to $2 \theta=12.44^{\circ}(0.711 \mathrm{~nm})$ in SAPC due to the intercalation of KL by polymer network. No obvious peaks were observed for SAP due to the amorphous structure. In contrast, SAPC showed the typical crystallite reflections associated with $K L$, which indicated that KL was uniformly dispersed in the polymer matrix, and an amorphous superabsorbent composite was synthesized.

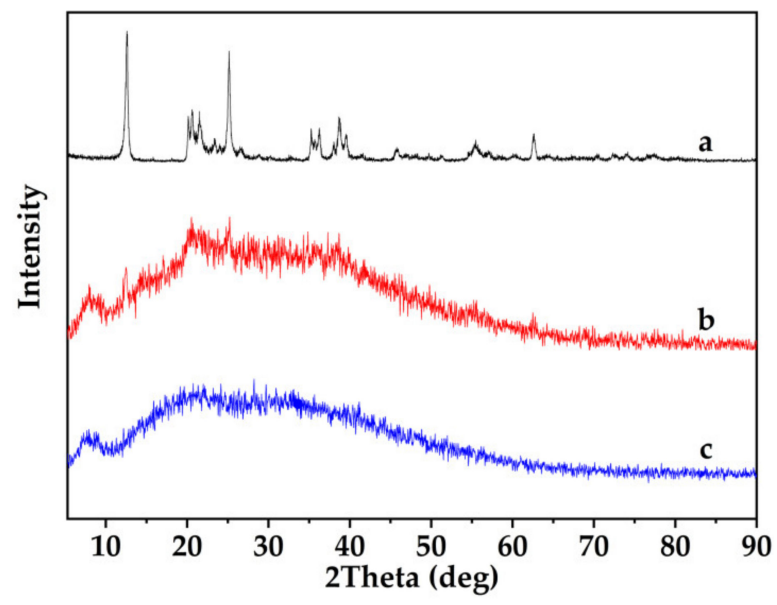

Figure 3. X-ray diffraction XRD patterns of (a) KL, (b) SAPC (4 wt. \% KL) and (c) SAP. 


\subsection{TGA Analysis}

The TGA curves of SAP and SAPC ( 4 wt. \% KL) are shown in Figure 4 . In the range from 35 to $203{ }^{\circ} \mathrm{C}$, the minor weight loss of SAP and SAPC was mainly ascribed to the evaporation of adsorbed moisture and bound water. The weight loss of SAP and SAPC at 203-343 ${ }^{\circ} \mathrm{C}$ were related to the dehydration of saccharide rings and breaking of the C-O-C bond in ST and SA chain. Also, the weight loss from $343{ }^{\circ} \mathrm{C}$ to $416{ }^{\circ} \mathrm{C}$ corresponded to the decomposition of the carboxyl groups of the copolymers. The major mass loss of SAP and SAPC occurred in the temperature range of $416-480{ }^{\circ} \mathrm{C}$ and $416-495^{\circ} \mathrm{C}$, which was due to the decomposition of the 3D network structure. It is noted between 343 and $495{ }^{\circ} \mathrm{C}$ that the decomposition rate of SAP was obviously higher than that of SAPC. Additionally, the weight residual of SAPC was $49.5 \%, 6.4 \%$ higher than that of SAP. These facts seem to indicate improved thermal stability of SAPC compared to that of SAP, probably owing to the heat dissipation impedance effect of KL.

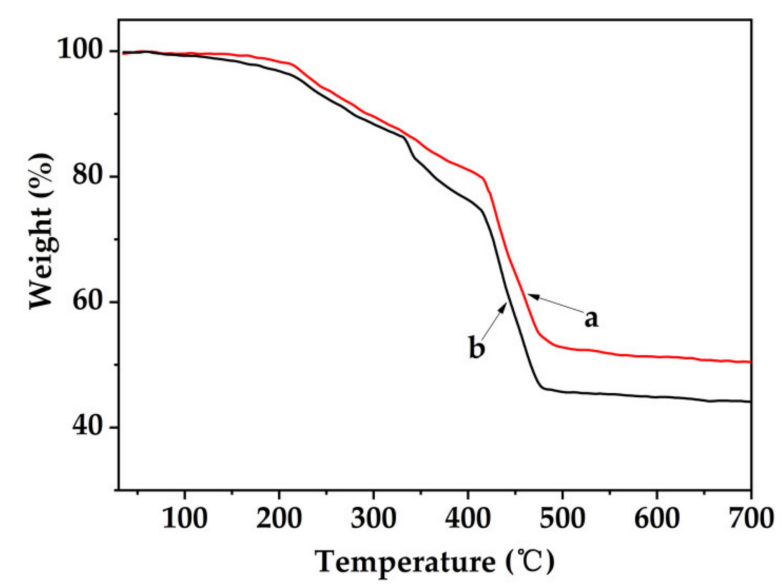

Figure 4. Thermal gravimetry analysis (TGA) curves of (a) SAP and (b) SAPC (4 wt. \% KL).

\subsection{Effects of Reaction Conditions on SAPC Performance}

\subsubsection{Effect of SA Content}

The effect of SA content on water absorption of SAPC is shown in Figure 5a. Water absorption increased from 736 to $933 \mathrm{~g} / \mathrm{g}$, with the SA content changing from $10 \mathrm{wt}$. \% to $15 \mathrm{wt}$. \%, and then decreased to $763 \mathrm{~g} / \mathrm{g}$, with SA content further increasing to $20 \mathrm{wt}$. \%. When the content of SA, which act as the basic skeleton, was too low, AA self-polymerized, resulting in the inability to form an effective 3D network to absorb water. With much higher SA content, sharply increased viscosity resulted in the system, restricting the monomer movement and reducing the conversion rate. Thus, a less developed 3D polymer network and suppressed water absorption capacity could be expected. 

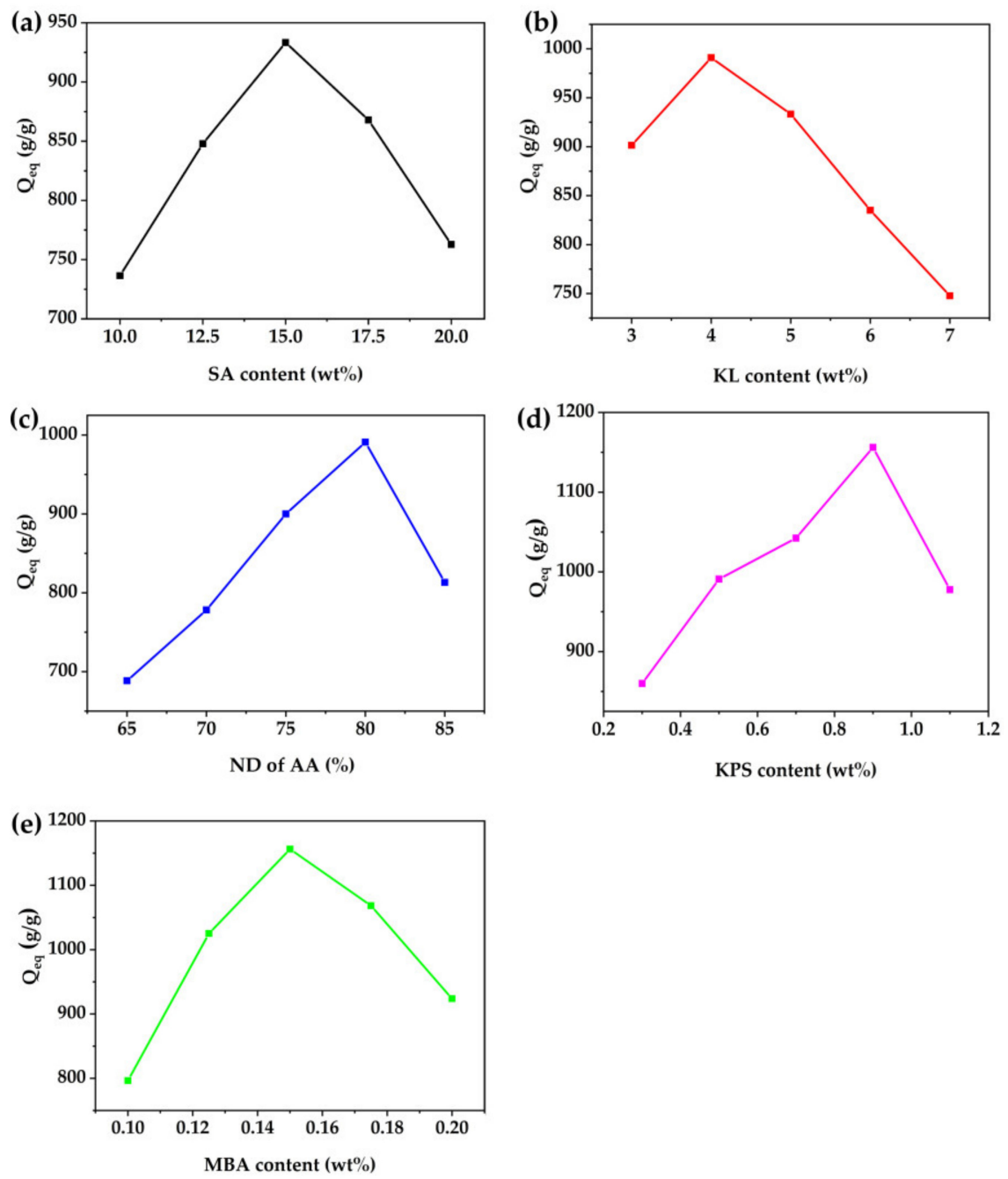

Figure 5. Effects of (a) SA content (ST = $15 \mathrm{wt} \%, \mathrm{KL}=5 \mathrm{wt} \%$, neutralization degree (ND) of acrylic acid $(\mathrm{AA})=80 \%$, potassium persulfate $(\mathrm{KPS})=0.5 \mathrm{wt} \%, \mathrm{~N}, \mathrm{~N}^{\prime}$-methylenebisacrylamide $(\mathrm{MBA})=0.15 \mathrm{wt} \%),(\mathrm{b}) \mathrm{KL}$ content $(\mathrm{ST}=15 \mathrm{wt} \%, \mathrm{SA}=15 \mathrm{wt} \%$, ND of AA $=80 \%, \mathrm{KPS}=0.5 \mathrm{wt} \%$, $\mathrm{MBA}=0.15 \mathrm{wt} \%),(\mathrm{c}) \mathrm{ND}$ of $\mathrm{AA}(\mathrm{ST}=15 \mathrm{wt} \%, \mathrm{SA}=15 \mathrm{wt} \%, \mathrm{KL}=4 \mathrm{wt} \%, \mathrm{KPS}=0.5 \mathrm{wt} \%$, $\mathrm{MBA}=0.15 \mathrm{wt} \%)$, (d) KPS content (ST $=15 \mathrm{wt} \%, \mathrm{SA}=15 \mathrm{wt} \%, \mathrm{KL}=4 \mathrm{wt} \%$, ND of AA $=80 \%$, $\mathrm{MBA}=0.15 \mathrm{wt} \%$ ) and (e) MBA content (ST $=15 \mathrm{wt} \%, \mathrm{SA}=15 \mathrm{wt} \%, \mathrm{KL}=4 \mathrm{wt} \%, \mathrm{ND}$ of AA $=80 \%$, KPS $=0.9 \mathrm{wt} \%$ ) on the water absorption of SAPC. These contents are based on the weight percentage of raw materials and AA $(20 \mathrm{~mL})$. $\mathrm{Q}_{\mathrm{eq}}$ represents the water absorption of swelling for $4 \mathrm{~h}$.

\subsubsection{Effect of KL Content}

Figure $5 \mathrm{~b}$ depicts the effect of KL content on water absorption. Water absorption of SAPC first increased and then decreased with the increase of KL content from $3 \mathrm{wt}$. \% to 7 wt. \%. KL with a large number of hydrophilic groups could be chemically cross-linked with a polymer chain, forming a cross-linked polymer network with KL particles as the additional cross-linking points. The introduction of appropriate KL particles weakens the hydrogen-bonding interaction between carboxyl groups in the polymer and reduces the physical entanglement of the grafted polymer network chain [34,35]. Nevertheless, with excessive KL ( $>4 \mathrm{wt}$. \%), the excess KL particles increased the degree of cross-linking, leading to a decrease of the penetration space of water molecules. In addition, the extra kaolin particles were also filled into the polymer network space in the form of physical filling. Yet the water absorption rate of KL itself was low, as a result, the water absorption of SAPC inevitably decreased. Therefore, appropriate KL loading is critical to obtaining SAPC with high water absorption capacity. 


\subsubsection{Effect of Neutralization Degree of AA}

The water absorptance capacity of SAPC was closely related to the neutralization degree (ND) of AA (Figure 5c). AA has higher reaction activity and polymerization rate than sodium acrylate [36]. Water absorption of SAPC increased as ND increased from $65 \%$ to $80 \%$. When ND was lower, the polymerization reaction completed rapidly within a short time, resulting in a highly cross-linked network structure with low swelling capacity. With the increase of ND, the polymerization rate decreased correspondingly. In addition, the increase of $-\mathrm{COO}^{-}$groups and $\mathrm{Na}^{+}$content in the polymer network increased both the repulsive force between the anions on the polymer chains and the osmotic pressure difference between the inside and outside of the polymer network, which was conducive to the entry of water or other small molecules [37-39]. However, when ND was higher than $80 \%$, water absorption dropped significantly, attributed to the reaction of $-\mathrm{COO}^{-}$groups with excess $\mathrm{Na}^{+}$, resulting in weakening of the repulsive force.

\subsubsection{Effect of KPS Content}

Water absorption was significantly affected by the initiator concentration and the average kinetic chain length. With low KPS content (0.3-0.9 wt. \%), an integral polymer network could not be formed due to the few grafting points and a large number of unreacted monomers in the reaction system. With too much KPS (0.9-1.1 wt. \%), the excessive free radicals terminated the propagating chains earlier, shortening the average kinetic chain length. In both scenarios, low water absorption capacity resulted (Figure 5d).

\subsubsection{Effect of MBA Content}

The effect of the MBA content on water absorption of SAPC is shown in Figure 5e. Water absorption of SAPC increased first and then decreased with the increase of MBA content from 0.1 to $0.2 \mathrm{wt}$. \%, and a maximum value of $1156 \mathrm{~g} / \mathrm{g}$ was achieved with 0.15 wt. \% MBA loading. Lower or higher MBA content resulted in reduced water absorption. The water absorption capacity of resin was closely related to its spatial network structure. When the content of MBA was not sufficient, cross-linking density was low and a complete spatial network structure could be established, leading to low water absorption and poor mechanical properties of SAPC. However, a higher concentration of MBA produced a denser cross-linked structure, which made it difficult for liquid molecules to enter.

The optimal reaction conditions of SAPC were when the masses of ST, SA, KL, KPS and MBA were 15 wt. $\%, 15$ wt. $\%, 4$ wt. $\%, 0.9$ wt. $\%$ and 0.15 wt. $\%$ of AA, respectively. The neutralization degree of AA was $80 \%$. In this work, SAP and SAPC were synthesized under the optimal conditions for further tests.

\subsection{Performance Tests of SAPC}

\subsubsection{Swelling Kinetics of SAPC in Distilled water}

The pseudo-second order swelling kinetics model (Equation (3)) and the Ritger-Peppas model (Equation (4)) were used to analyze the experimental swelling data to evaluate the swelling behavior of SAPC, with results shown in Figure 6a,b [40-42]:

$$
\begin{gathered}
\frac{t}{q_{t}}=\frac{1}{\left(k_{2} q_{e}^{2}\right)}+\frac{t}{q_{e}} \\
F=\frac{q_{t}}{q_{e}}=\mathrm{kt}^{n}
\end{gathered}
$$



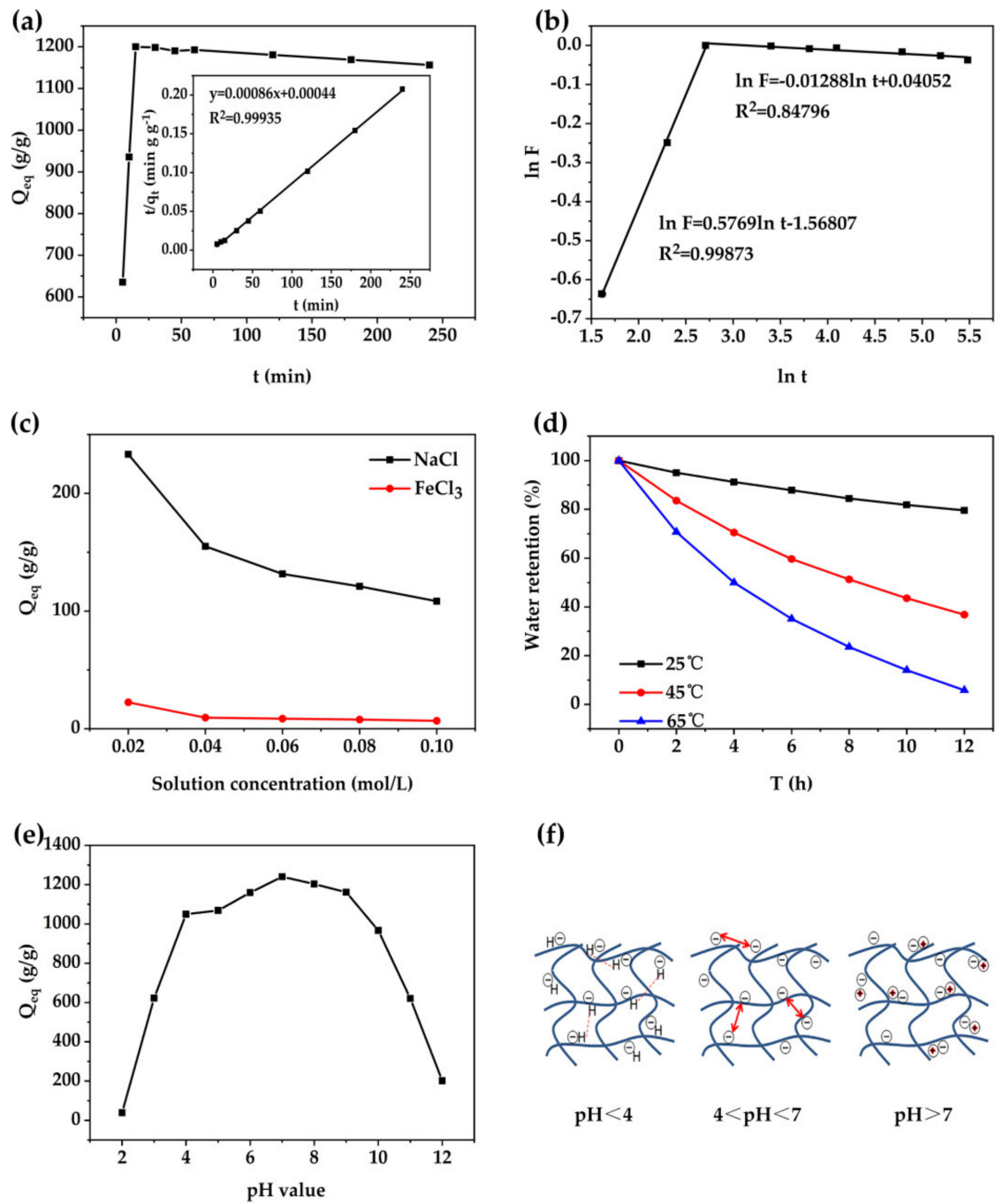

(f)

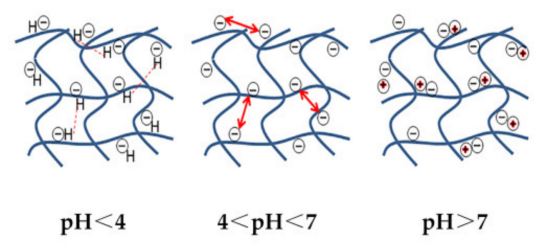

Figure 6. (a,b) Swelling kinetics of SAPC (4 wt. \% KL), (c) Swelling capacity in different salt solutions, (d) Water retention at different temperatures, (e) The swelling capacity of SAPC (4 wt. \% KL) in different $\mathrm{pH}$ solutions and (f) the swelling mechanism at various $\mathrm{pH}$ values.

To calculate $n$ and $k$, take the natural logarithm of Equation (4):

$$
\ln F=\ln \left(\frac{q_{t}}{q_{e}}\right)=\ln k+n \ln t
$$

where $t$ is absorption time and $k_{2}$ is the rate constant of the pseudo-second order model. $q_{t}$ and $q_{e}$ correspond to water absorption of SAPC at time $t$ and at equilibrium, respectively. $F$ denotes fractional uptake at time $t . k$ and $n$ are the characteristic constants of the polymer and the diffusion index, respectively.

From Figure 6a, water absorption of SAPC increased rapidly in the first 15 min, reached swelling equilibrium at $15 \mathrm{~min}$, and then stabilized after $15 \mathrm{~min}$. The maximum water absorption was $1200 \mathrm{~g} / \mathrm{g}$. It was also found that the relationship curve between $t$ and $t / q_{t}$ was linear with $\mathrm{R}^{2}$ value $(0.99935)$ close to 1 , indicating that the swelling behavior of SAPC could be fitted by the pseudo-second order kinetics model. Since this model is based on chemical adsorption assumptions, it suggests that the chemisorption was the main way of the water absorption process.

Based on the polymer chain relaxation rate and the relative diffusion rate of water into the polymer network, the water diffusion mechanism can be classified into five types. That is, pseudo-Fickian diffusion $(n<0.5)$, Fickian diffusion $(n=0.5)$, non-Fickian diffusion 
$(0.5<n<1.0)$, Case II transport diffusion $(n=1)$ and relaxed diffusion $(n>1)$ [43-45]. These equations were applied to the initial stages of swelling. According to Figure 6b, within $0-15 \mathrm{~min}, 0.5<n<1$, indicating that the water diffusion mechanism was consistent with the non-Fickian diffusion mechanism, the diffusion and relaxation were considered to be isochronally effective. After $15 \mathrm{~min}, n<0.5$, the main reason of swelling was the diffusion of water molecules in the polymer network.

\subsubsection{Swelling Behavior in Salt Solutions}

The influences of cation and saline type on water absorption were studied using $\mathrm{FeCl}_{3}$ and $\mathrm{NaCl}$, with results shown in Figure 6c. For the same saline solution, as cation concentration increased, water absorption of SAPC decreased. This result was due to the charge screening effect of cations, which reduced the osmotic pressure difference between the polymer network and the external saline solution and decreased the repulsive force between the $-\mathrm{COO}^{-}$groups of the polymer chain. Comparing the two absorption curves, it was found that water absorption of SAPC was lower in the multivalent cation solution. This is attributed to the complexation between carboxylate anions of chains and multivalent cations, resulting in an increase of the network cross-linking density and a drastic decrease in water absorption $[46,47]$.

\subsubsection{Water Retention Properties}

The water retention of fully swollen SAPC at different temperatures, i.e., 25, 45 and $60{ }^{\circ} \mathrm{C}$, was studied, and the results are shown in Figure $6 \mathrm{~d}$. As can be seen, water retention of SAPC decreased with time, and the water retention curve at $25{ }^{\circ} \mathrm{C}$ was gentler than that at 45 and $60{ }^{\circ} \mathrm{C}$. At $25^{\circ} \mathrm{C}$, the water retention rate was about $80 \%$ after $12 \mathrm{~h}$. However, the water retention rate of SAPC at $45^{\circ} \mathrm{C}$ and $60^{\circ} \mathrm{C}$ still reached about $37 \%$ and $6 \%$ after $12 \mathrm{~h}$, respectively. The above results showed that SAPC had excellent water retention ability and thus broad application prospects.

\subsubsection{Swelling Behavior in Buffer Solutions}

As a new superabsorbent composite, the swelling capacity in different $\mathrm{pH}$ solutions has great influence on its application in various fields. Hence, the swelling behavior of SAPC in different buffer solutions was studied, with results shown in Figure 6e and the mechanism illustrated in Figure 6f. At low $\mathrm{pH}$ values $(\mathrm{pH} \leq 4)$, due to the higher concentration of $\mathrm{H}^{+}$, most of the $-\mathrm{COO}^{-}$groups were transformed into -COOH groups, which weakened the electrostatic repulsion between $-\mathrm{COO}^{-}$groups and strengthened the hydrogen-bonding interaction between the -COOH groups of polymer chains [48]. Therefore, water absorption was low. With an increase of $\mathrm{pH}$ value $(4 \leq \mathrm{pH} \leq 7)$, water absorption of SAPC increased, owing to gradual ionization of -COOH groups, which resulted in an increase of electrostatic repulsion between $-\mathrm{COO}^{-}$groups. At a high $\mathrm{pH}$ value $(\mathrm{pH} \geq 7)$, as $\mathrm{Na}^{+}$concentration increased in the solution, water absorption decreased correspondingly. The decrease was due to the charge shielding effect of excessive $\mathrm{Na}^{+}$on the $-\mathrm{COO}^{-}$groups, which weakened the electrostatic repulsion force and reduced the osmotic pressure difference between the inside and outside of the polymer network. Generally, this type of SAPC had excellent $\mathrm{pH}$ tolerance between 4 and 10.

\section{Conclusions}

To summarize, a series of SAPC was successfully prepared by free radical polymerization of SA, ST, AA and KL in aqueous solution. The optimal reaction conditions of SAPC were achieved when the mass of ST, SA, KL, KPS and MBA were 15 wt. \%, 15 wt. \%, 4 wt. \%, 0.9 wt. $\%$ and $0.15 \mathrm{wt}$. \% of AA, respectively, with a neutralization degree of AA $80 \%$. With optimized reactants concentrations, a maximum water absorption of $1200 \mathrm{~g} / \mathrm{g}$ was obtained. FT-IR spectra confirmed the success of the polymerization reaction. SEM images revealed the rough and porous surface of SAPC which was conducive to the liquid entering into the polymer network. XRD patterns proved that KL was uniformly dispersed in the 
polymer matrix. TGA spectra indicated that the addition of KL improved the thermal stability of SAPC. The swelling kinetic of SAPC was studied, showing that the swelling behavior of SAPC followed the pseudo-second order kinetic model and the non-Fickian diffusion model. Along with excellent water absorption capacity, the fabricated SAPC also had excellent water retention property, good salt tolerance in monovalent salt solution and $\mathrm{pH}$ tolerance between 4 and 10, making it promising in many applications.

Author Contributions: Conceptualization, M.C. and Z.W.; methodology, M.C. and Z.W.; validation, M.C. and Z.W.; formal analysis, M.C. and Z.W.; investigation, M.C., C.Z., B.C.; resources, M.C., Z.L., Z.W.; data curation, M.C., C.Z., B.C.; writing-original draft preparation, M.C. and Z.W.; writingreview and editing, M.C., X.C., Z.W.; visualization, M.C. and Z.W.; supervision, D.Z. and Z.W.; project administration, Z.W.; funding acquisition, M.C. and Z.W. All authors have read and agreed to the published version of the manuscript.

Funding: This work was supported by grants from the National Natural Science Foundation of China (contract grant number 31270608) and the Heilongjiang Educational Committee (contract grant number 1511385).

Institutional Review Board Statement: Not applicable.

Informed Consent Statement: Not applicable.

Data Availability Statement: Data availability upon request.

Conflicts of Interest: The authors declare no conflict of interests.

\section{References}

1. Fang, S.; Wang, G.; Xing, R.; Chen, X.; Liu, S.; Qin, Y.; Li, K.; Wang, X.; Li, R.; Li, P. Synthesis of superabsorbent polymers based on chitosan derivative graft acrylic acid-co-acrylamide and its property testing. Int. J. Biol. Macromol. 2019, 132, 575-584. [CrossRef] [PubMed]

2. Adair, A.; Kaesaman, A.; Klinpituksa, P. Superabsorbent materials derived from hydroxyethyl cellulose and bentonite: Preparation, characterization and swelling capacities. Polym. Test. 2017, 64, 321-329. [CrossRef]

3. Mu, Y.; Du, D.; Yang, R.; Xu, Z. Preparation and performance of poly(acrylic acid-methacrylic acid)/montmorillonite microporous superabsorbent nanocomposite. Mater. Lett. 2015, 142, 94-96. [CrossRef]

4. Alam, M.N.; Christopher, L.P. Natural Cellulose-Chitosan Cross-Linked Superabsorbent Hydrogels with Superior Swelling Properties. ACS Sustain. Chem. Eng. 2018, 6, 8736-8742. [CrossRef]

5. Wan, T.; Zhou, Z.; Huang, R.; Zou, C.; Xu, M.; Cheng, W.; Li, R. Synthesis and swelling properties of microcrystal muscovite composite superabsorbent. Appl. Clay Sci. 2014, 101, 199-204. [CrossRef]

6. Cheng, S.; Liu, X.; Zhen, J.; Lei, Z. Preparation of superabsorbent resin with fast water absorption rate based on hydroxymethyl cellulose sodium and its application. Carbohydr. Polym. 2019, 225, 115214. [CrossRef]

7. Zhang, Q.; Wang, Z.; Zhang, C.; Aluko, R.E.; Yuan, J.; Ju, X.; He, R. Structural and functional characterization of rice starch-based superabsorbent polymer materials. Int. J. Biol. Macromol. 2020, 153, 1291-1298. [CrossRef]

8. Sawut, A.; Yimit, M.; Sun, W.; Nurulla, I. Photopolymerisation and characterization of maleylatedcellulose-g-poly(acrylic acid) superabsorbent polymer. Carbohydr. Polym. 2014, 101, 231-239. [CrossRef]

9. Essawy, H.A.; Ghazy, M.B.M.; Abd El-Hai, F.; Mohamed, M.F. Superabsorbent hydrogels via graft polymerization of acrylic acid from chitosan-cellulose hybrid and their potential in controlled release of soil nutrients. Int. J. Biol. Macromol. 2016, 89, 144-151. [CrossRef]

10. Nagarpita, M.V.; Roy, P.; Shruthi, S.B.; Sailaja, R.R.N. Synthesis and swelling characteristics of chitosan and CMC grafted sodium acrylate-co-acrylamide using modified nanoclay and examining its efficacy for removal of dyes. Int. J. Biol. Macromol. 2017, 102, 1226-1240. [CrossRef]

11. Chen, Y.; Tang, H.; Liu, Y.; Tan, H. Preparation and study on the volume phase transition properties of novel carboxymethyl chitosan grafted polyampholyte superabsorbent polymers. J. Taiwan Inst. Chem. Eng. 2016, 59, 569-577. [CrossRef]

12. Álvarez-Castillo, E.; Bengoechea, C.; Guerrero, A. Composites from by-products of the food industry for the development of superabsorbent biomaterials. Food Bioprod. Process. 2020, 119, 296-305. [CrossRef]

13. Fang, S.; Wang, G.; Li, P.; Xing, R.; Liu, S.; Qin, Y.; Yu, H.; Chen, X.; Li, K. Synthesis of chitosan derivative graft acrylic acid superabsorbent polymers and its application as water retaining agent. Int. J. Biol. Macromol. 2018, 115, 754-761. [CrossRef]

14. Yadav, M.; Rhee, K.Y. Superabsorbent nanocomposite (alginate-g-PAMPS/MMT): Synthesis, characterization and swelling behavior. Carbohydr. Polym. 2012, 90, 165-173. [CrossRef]

15. Ge, X.; Chang, M.; Jiang, W.; Zhang, B.; Xing, R.; Bulin, C. Selective location of kaolin and effects of maleic anhydride in kaolin/poly(E-caprolactone)/poly(lactic acid) composites. Appl. Clay Sci. 2020, 189, 105524. [CrossRef] 
16. Pourjavadi, A.; Ayyari, M.; Amini-Fazl, M.S. Taguchi optimized synthesis of collagen-g-poly(acrylic acid)/kaolin composite superabsorbent hydrogel. Eur. Polym. J. 2008, 44, 1209-1216. [CrossRef]

17. Bao, Y.; Ma, J.; Sun, Y. Swelling behaviors of organic/inorganic composites based on various cellulose derivatives and inorganic particles. Carbohydr. Polym. 2012, 88, 589-595. [CrossRef]

18. Zhang, J.; Chen, H.; Wang, A. Study on superabsorbent composite. III. Swelling behaviors of polyacrylamide/attapulgite composite based on acidified attapulgite and organo-attapulgite. Eur. Polym. J. 2005, 41, 2434-2442. [CrossRef]

19. Shalvir, A.; Liu, Q.; Abdekhodaie, M.J.; Wu, X.Y. Novel modified starch-xanthan gum hydrogels for controlled drug delivery: Synthesis and characterization. Carbohydr. Polym. 2010, 79, 898-907. [CrossRef]

20. Dragan, E.S.; Apopei, D.F. Synthesis and swelling behavior of pH-sensitive semi-interpenetrating polymer network composite hydrogels based on native and modified potatoes starch as potential sorbent for cationic dyes. Chem. Eng. J. 2011, 178, 252-263. [CrossRef]

21. Phang, Y.; Chee, S.; Lee, C.; Teh, Y. Thermal and microbial degradation of alginate-based superabsorbent polymer. Polym. Degrad. Stabil. 2011, 96, 1653-1661. [CrossRef]

22. Pereira, R.; Carvalho, A.; Vaz, D.C.; Gil, M.H.; Mendes, A.; Bártolo, P. Development of novel alginate based hydrogel films for wound healing applications. Int. J. Biol. Macromol. 2013, 52, 221-230. [CrossRef] [PubMed]

23. Olad, A.; Doustdar, F.; Gharekhani, H. Fabrication and characterization of a starch-based superabsorbent hydrogel composite reinforced with cellulose nanocrystals from potato peel waste. Colloid Surf. A-Physicochem. Eng. Asp. 2020, 601, 124962. [CrossRef]

24. Karadă̆, E.; Topag, F.; Kundakci, S.; Üzüm, Ö.B. Novel composite sorbent AAm/MA hydrogels containing starch and kaolin for water sorption and dye uptake. Bull. Mater. Sci. 2014, 37, 1637-1646. [CrossRef]

25. Wu, J.; Wei, Y.; Lin, J.; Lin, S. Study on starch-graft-acrylamide/mineral powder superabsorbent composite. Polymer. 2003, 44, 6513-6520. [CrossRef]

26. Zhu, L.; Guan, C.; Zhou, B.; Zhang, Z.; Yang, R.; Tang, Y.; Yang, J. Adsorption of Dyes onto Sodium Alginate Graft Poly(Acrylic Acid-co-2-Acrylamide-2-Methyl Propane Sulfonic Acid)/ Kaolin Hydrogel Composite. Polym. Polym. Compos. 2017, 25, 627-634. [CrossRef]

27. Tang, Y.; Wang, Q.; Zhou, B.; Ma, D.; Ma, Z.; Zhu, L. Synthesis of Sodium Alginate Graft Poly(Acrylic Acid-Co-Acrylamide)/ Kaolin Composite Hydrogel and the Study on Its Sorption of Rhodamine B. Polym. Polym. Compos. 2015, 23, 467-474. [CrossRef]

28. Sorour, M.; El-Sayed, M.; El Moneem, N.A.; Talaat, H.; Shaalan, H.; El Marsafy, S. Free radical grafting kinetics of acrylamide onto a blend of starch/chitosan/alginate. Carbohydr. Polym. 2013, 98, 460-464. [CrossRef]

29. Lee, J.; Park, S.; Roh, H.; Oh, S.; Kim, S.; Kim, M.; Kim, D.; Park, J. Preparation and Characterization of Superabsorbent Polymers Based on Starch Aldehydes and Carboxymethyl Cellulose. Polymers 2018, 10, 605. [CrossRef]

30. Lan, G.; Zhang, M.; Liu, Y.; Qiu, H.; Xue, S.; Zhang, T.; Xu, Q. Synthesis and Swelling Behavior of Super-Absorbent Soluble Starch-g-poly(AM-co-NaAMC ${ }_{14}$ S) Through Graft Copolymerization and Hydrolysis. Starch/Stärke 2019, 71, 1800272. [CrossRef]

31. Qiao, D.; Yu, L.; Bao, X.; Zhang, B.; Jiang, F. Understanding the microstructure and absorption rate of starch-based superabsorbent polymers prepared under high starch concentration. Carbohydr. Polym. 2017, 175, 141-148. [CrossRef]

32. Gharekhani, H.; Olad, A.; Mirmohseni, A.; Bybordi, A. Superabsorbent hydrogel made of NaAlg-g-poly(AA-co-AAm) and rice husk ash: Synthesis, characterization, and swelling kinetic studies. Carbohydr. Polym. 2017, 168, 1-13. [CrossRef]

33. Wang, W.; Wang, A. Synthesis and swelling properties of $\mathrm{pH}$-sensitive semi-IPN superabsorbent hydrogels based on sodium alginate-g-poly(sodium acrylate) and polyvinylpyrrolidone. Carbohydr. Polym. 2010, 80, 1028-1036. [CrossRef]

34. Shi, X.; Wang, W.; Kang, Y.; Wang, A. Enhanced Swelling Properties of a Novel Sodium Alginate-Based Superabsorbent Composites: NaAlg-g-poly(NaA-co-St)/APT. J. Appl. Polym. Sci. 2012, 125, 1822-1832. [CrossRef]

35. Feng, E.; Ma, G.; Wu, Y.; Wang, H.; Lei, Z. Preparation and properties of organic-inorganic composite superabsorbent based on xanthan gum and loess. Carbohydr. Polym. 2014, 111, 463-468. [CrossRef]

36. Zhang, J.; Zhang, F. Recycling waste polyethylene film for amphoteric superabsorbent resin Synthesis. Chem. Eng. J. 2018, 331, 169-176. [CrossRef]

37. Shi, X.; Wang, W.; Wang, A. Effect of surfactant on porosity and swelling behaviors of guar gum-g-poly(sodium acrylate-costyrene)/attapulgite superabsorbent hydrogels. Colloid Surf. B Biointerfaces 2011, 88, 279-286. [CrossRef] [PubMed]

38. Rashidzadeh, A.; Olad, A. Slow-released NPK fertilizer encapsulated by NaAlg-g-poly(AA-co-AAm)/MMT superabsorbent nanocomposite. Carbohydr. Polym. 2014, 114, 269-278. [CrossRef]

39. Behrouzi, M.; Moghadam, P.N. Synthesis of a new superabsorbent copolymer based on acrylic acid grafted onto carboxymethyl tragacanth. Carbohydr. Polym. 2018, 202, 227-235. [CrossRef]

40. Zhang, J.; Zhang, F. A new approach for blending waste plastics processing: Superabsorbent resin synthesis. J. Clean Prod. 2018, 197, 501-510. [CrossRef]

41. Motamedi, E.; Motesharezedeh, B.; Shirinfekr, A.; Samar, S.M. Synthesis and swelling behavior of environmentally friendly starch-based superabsorbent hydrogels reinforced with natural char nano/micro particles. J. Environ. Chem. Eng. 2020, 8, 103583. [CrossRef]

42. Diao, M.; Li, Q.; Xiao, H.; Duan, N.; Xu, J. Synthesis and adsorption properties of superabsorbent hydrogel and peanut hull composite. J. Environ. Chem. Eng. 2014, 2, 1558-1567. [CrossRef]

43. Ahmed, E.M.; Aggor, F.S.; Awad, A.M.; El-Aref, A.T. An innovative method for preparation of nanometal hydroxide superabsorbent Hydrogel. Carbohydr. Polym. 2013, 91, 693-698. [CrossRef] 
44. Dalaran, M.; Emik, S.; Güçlü, G.; İyim, T.B.; Özgümüş, S. Study on a novel polyampholyte nanocomposite superabsorbent hydrogels: Synthesis, characterization and investigation of removal of indigo carmine from aqueous solution. Desalination 2011, 279, 170-182. [CrossRef]

45. Olad, A.; Doustdar, F.; Gharekhani, H. Starch-based semi-IPN hydrogel nanocomposite integrated with clinoptilolite: Preparation and swelling kinetic study. Carbohydr. Polym. 2018, 200, 516-528. [CrossRef]

46. Pourjavadi, A.; Ghasemzadeh, H.; Soleyman, R. Synthesis, Characterization, and Swelling Behavior of Alginate-g-Poly(sodium acrylate)/Kaolin Superabsorbent Hydrogel Composites. J. Appl. Polym. Sci. 2007, 105, 2631-2639. [CrossRef]

47. Ma, G.; Yang, Q.; Ran, F.; Dong, Z.; Lei, Z. High performance and low cost composite superabsorbent based on polyaspartic acid and palygorskite clay. Appl. Clay Sci. 2015, 118, 21-28. [CrossRef]

48. He, G.; Ke, W.; Chen, X.; Kong, Y.; Zheng, H.; Yin, Y.; Cai, W. Preparation and properties of quaternary ammonium chitosan-gpoly(acrylic acid-co-acrylamide) superabsorbent hydrogels. React. Funct. Polym. 2017, 111, 14-21. [CrossRef] 